\title{
Interações entre díades mãe-criança que apresentam a linguagem expressiva típica e díades mãe-criança que apresentam a linguagem expressiva atrasada
}

\author{
Renata Meira Véras \\ Nádia Maria Ribeiro Salomão \\ Universidade Federal da Paraíba
}

\begin{abstract}
RESUMO
O objetivo geral deste estudo foi o de investigar os aspectos interacionais de díades mães-crianças com atraso na linguagem expressiva e de mães-crianças com desenvolvimento típico da linguagem, sob a Perspectiva da Interação Social dos Estudiosos da Linguagem. Participaram deste estudo 12 díades mãe-criança, com idades das crianças de 24-36 meses, distribuídas igualmente nos dois grupos de crianças. As díades foram filmadas em situação de brinquedo livre e o registro e a análise dos dados foram realizados com o auxílio do sistema computacional CHILDES (Child Language Data Exchange System). Através do teste de comparação de duas proporções, verificou-se que existem variações na fala materna dirigida a estes dois grupos de crianças. A análise das categorias de contingência semântica maternas apontou que foram mais utilizados enunciados de continuidade com as crianças típicas. Observou-se que as crianças com desenvolvimento atrasado da linguagem receberam enunciados mais diretivos, e que as mães apresentaram mais requisições às crianças com o desenvolvimento típico da linguagem. Tais dados foram analisados considerando-se que as crianças de desenvolvimento típico da linguagem apresentaram mais fala espontânea e respostas verbais adequadas e que as crianças com atraso no desenvolvimento da linguagem apresentaram mais respostas não-verbais, repetição espontânea e ausência de respostas. Esses aspectos enfatizam a importância de se considerar tanto a influência do input lingüístico materno como as características da criança.
\end{abstract}

Palavras-chave: interação mãe-criança; desenvolvimento típico da linguagem expressiva e desenvolvimento da linguagem expressiva atrasada.

\section{ABSTRACT \\ Mother-child interaction: child with typical development in expressive language and child with late language development}

The main objective of this study was to investigate the interactional aspects of mother-child relation with late development in expressive language and mother-child with typical language development based on the social interaction perspective. Participated in this study twelve mother-child dyads, with children aged from 24 to 36 months equally distributed between two children groups. The motherchild interactions were recorded in a free play situation, and the data registrations and analysis were carried out using the CHILDES (Child Language Data Exchange System) computer program. Through the comparison using proportions test, it was verified that there were variations on mother's conversation directed to these two groups of children. The analysis of the mother's semantic contingency pointed that the used continuity expressions with children that presented typical language development. It was observed that children with late development in expressive language received more directive expressions, and mothers presented more requests to children with typical language development. data were analyzed considering that children with typical language development presented more spontaneous speech and adequate verbal answers, and children with late development in expressive language presented more non-verbal answers, spontaneous repetition and no answers. These aspects emphasizes the importance of considering the influence of both maternal linguistic input and child characteristics.

Keywords: mother-child interaction; typical language development and late development in expressive language.

\section{INTRODUÇÃO}

A linguagem pode ser compreendida como a primeira forma de comunicação do ser humano, permitindo o acesso direto ou indireto a valores, crenças e regras que regem o mundo ao seu redor. Assim, a criança, antes mesmo de aprender a falar, terá acesso através da linguagem aos conhecimentos de sua cultura.
A Perspectiva da Interação Social dos Estudiosos da Linguagem, que fundamenta o presente trabalho, surgiu como uma tentativa de estabelecer um compromisso entre dois extremos sobre a aquisição da linguagem, a influência ambiental e a influência biológica. 
O input materno é um dos principais aspectos estudados na aquisição da linguagem pela perspectiva da interação social. Segundo Garton (1992), um dos aspectos que norteiam essa vertente teórica é o destaque dado não somente à forma mas também à função da fala materna, assim como à concepção da criança enquanto um processador ativo do input a ela dirigido.

Segundo Luque e Villa (1997), os inputs lingüísticos correspondem a um arcabouço de conhecimentos a respeito da língua no meio em que a criança está inserida, e que lhes são passados durante as interações sociais. Para esses autores, o input lingüístico veicula os modelos socioculturais da mesma forma que identifica um grupo social. Nesse sentido, o indivíduo se expõe à influência dos modelos da comunidade, visando manter uma interação com os membros do grupo. Assim, a linguagem do meio ambiente, aquela com a qual a criança tem contato desde os primeiros anos de vida, desempenha um papel imprescindível no avanço de seu crescimento lingüístico.

Os estudiosos da perspectiva da interação social (Snow, 1977; Garton, 1992), afirmam que a forma das mães falarem a seus filhos é caracterizada por um léxico e estruturas sintáticas diferentes daquela utilizada na fala com os adultos. Essa diferença ocorre porque: a) as mães utilizam procedimentos facilitadores da compreensão, tendem a enfatizar as palavras essenciais numa frase, diminuir a velocidade da fala e repetir o que disseram, caso a criança não tenha entendido (Snow, 1972); b) as mães utilizam uma fala sintaticamente mais simples, com vocabulário e complexidade preposicional limitados (Snow, 1972); c) a linguagem materna é restrita ao 'aqui e agora', conjugada no tempo presente e referente a objetos visíveis e comentários sobre atividades contínuas (Snow, 1977); d) as mães empregam um número de características especiais na fala apresentada à criança, cuja intenção é envolvê-la na interação, clarificando e elevando sua contribuição (Snow, 1977).

Considerando-se que o input desempenha uma forte influência na aquisição da linguagem da criança os teóricos da abordagem da Interação Social seguem o pressuposto de que a díade mãe-criança corresponde a um sistema de interação dinâmica e bidirecional, caracterizado por necessidades e contribuições mútuas (Mussen, Conger, Kagan \& Huston, 1995).

O papel do input precisa ser analisado enfatizandose as características individuais e os aspectos sociais relacionados à criança e à mãe, tornando necessário uma análise interacional e bidirecional desta relação. A importância de se levar em conta tais características encontra-se no fato de que existe variabilidade de uma criança para outra, de uma mãe para outra, na forma e na medida em que ministram e fazem uso de aspectos particulares da linguagem. Ademais, segundo Pine
(1994), o nível de desenvolvimento da criança, em termos de idade ou de estágio linguístico, influencia a forma como ela fará uso do input recebido; um determinado input materno poderá ter efeitos facilitadores da linguagem em um nível de desenvolvimento da criança, e não apresentar esse mesmo efeito em um outro nível.

As crianças com atraso no desenvolvimento da linguagem expressiva não apresentam uma etiologia conhecida. Os termos "distúrbio de linguagem", "atraso de linguagem" e "desvio de linguagem" são outros termos que têm sido utilizados para fazer referência a esta população de crianças com problemas de linguagem de natureza não-orgânica (Craig, 1997). Atualmente Stark e Tallal (1981) as identificam através de critérios de exclusão: nenhuma perda auditiva ou historia de otite média recorrente a longo prazo; nenhum problema emocional ou comportamental significativo; ausência de inteligência abaixo da média; nenhum problema neurológico e nenhum defeito sensorial ou oral.

De acordo com Snow (1997), o enfoque destes estudos nas crianças com atrasos no desenvolvimento da linguagem, foi voltado essencialmente para o input, por várias razões: 1) as hipóteses sobre as características da criança que controla o input recebido podem ser testadas em populações em que as habilidades lingüísticas e as capacidades cognitivas estão menos estreitamente ligadas do que em crianças com desenvolvimento típico; 2) a compreensão do ambiente linguístico das crianças com diversos tipos de deficiências pode contribuir para um melhor tratamento ou prevenção das sequielas na linguagem; e 3) as crianças com atrasos ou deficiências no desenvolvimento podem constituir uma excelente oportunidade para testar os efeitos facilitadores ou que constituem pré-requisito do input no desenvolvimento normal da linguagem.

Estudos sobre a interação mãe-criança com atraso no desenvolvimento da linguagem expressiva têm mostrado resultados controvertidos. Alguns estudos indicam que essas crianças recebem um input diferenciado de outras crianças (Moseley, 1990), enquanto outros estudos defendem que não existem diferenças significativas na fala dirigida a crianças com atraso na linguagem e às crianças normais que estão no mesmo nível lingüístico, e sugerem ainda, que a fala materna é controlada pelo nível lingüístico da criança (ContiRamsden, 1994).

Snow (1997) ainda assinala que não existe um consenso entre os autores no que diz respeito a quais estilos de input são favoráveis à aquisição da linguagem por parte da criança. Entretanto, existe, por outro lado, um grande número de evidências sobre os quais estilos de input podem facilitar o desenvolvimento lingüístico da criança e quais podem inibir seu percur- 
so "normal". Estas evidências devem ser interpretadas com cautela, visto que não se têm claramente definido quais fatores são as causas e quais fatores são os efeitos, ou seja, se é o estilo do input que influencia o desenvolvimento da linguagem da criança, ou se são as características presentes na criança que influenciam a qualidade do input (Rice, 1989).

A continuidade para Rice (1989) é um estilo relevante da fala materna que facilita o desenvolvimento da linguagem, definida como a combinação imediata do enunciado do adulto com o conteúdo ou tópico da fala da criança, onde se tem como resultados a continuidade da conversação, permitindo à criança maior participação na conversação.

A reformulação constitui os enunciados maternos que a mãe repete a frase proferida pela criança, modificando-a, enriquecendo seu vocabulário. Para ContiRamsden (1994) a ausência de reformulações no input materno tem sido apontada como um dos fatores explicativos no atraso da fala das crianças.

Quanto aos estilos de input que podem interferir negativamente no desenvolvimento da linguagem, um dos mais citados é a diretividade. Para Salomão e Conti-Ramsdem (1994) este é o enunciado materno, expresso de forma imperativa, que tem por função chamar a atenção, regular ou dirigir as verbalizações ou comportamentos da criança. Está associado a um desenvolvimento mais lento da linguagem normal da criança.

Considerando a importância da interação mãecriança para o desenvolvimento lingüístico, questionase a variação da dinâmica desta interação para o desenvolvimento lingüístico atrasado ou tardio da criança. Quais seriam os estilos lingüísticos presentes nas interações mãe-criança que apresentam o desenvolvimento típico da linguagem expressiva e mãe-criança que apresentam atraso no desenvolvimento da linguagem expressiva?

Pesquisar essas variações lingüísticas torna-se essencial para obter-se uma maior compreensão do estilo das interações mãe-criança que apresentam atraso na linguagem expressiva, considerando-se que o input materno tanto influencia como é influenciado pelas características da criança. Esta hipótese encontra suporte na literatura que sugere que alguns estilos são mais facilitadores do desenvolvimento da linguagem e outros tendem a inibir este desenvolvimento.

Com relação aos estilos comunicativos maternos dirigidos a crianças com atraso no desenvolvimento da linguagem expressiva e crianças com desenvolvimento típico da linguagem expressiva, os objetivos específicos são verificar e analisar a freqüência dos comportamentos comunicativos maternos verbais e suas funções, especificamente os diretivos, apresentados às crianças; a frequiência dos comportamentos comunicativos infantis, especificamente a fala espontânea e as respostas verbais e não-verbais, apresentados às mães.

\section{MÉTODO}

\section{Participantes}

Participaram deste estudo 12 pares de mãe-criança, com idade da criança de 24-36 meses, provindas de classe econômico-social média, sendo 6 pares de crianças com desenvolvimento atrasado da linguagem e 6 pares de crianças com desenvolvimento típico da linguagem. Em nenhuma das crianças observou-se afecções auditivas e/ou neurológicas. O critério de inclusão das crianças com atraso da linguagem expressiva é que as mesmas estivessem em acompanhamento fonoaudiológico. O diagnóstico dado pela fonoaudióloga seria atraso simples de linguagem, e para classificar estas crianças como tal, os critérios utilizados por esta profissional seriam os mesmos utilizados por Stark e Tallal (1981): não deveria ser observado nessas crianças nenhuma perda auditiva ou otite média recorrente a longo prazo; nenhum problema emocional significativo; ausência de inteligência abaixo da média; nenhum problema neurológico e nenhum problema sensorial ou oral.

\section{Instrumentos e situação}

Foram realizadas entrevistas com as mães do tipo semi-estruturadas registradas por meio de um gravador; filmagens das observações da interação mãecriança em situação de brinquedo livre, registradas através de uma câmara de vídeo.

\section{Procedimentos}

Os participantes que apresentavam a linguagem expressiva atrasada foram contatados em clínicas fonoaudiológicas e através de familiares e amigos. E os participantes que apresentavam a linguagem expressiva típica foram escolhidos aleatoriamente através do banco de dados do núcleo de estudos Interação Social e Desenvolvimento Infantil da Universidade Federal da Paraíba, Programa de Pós-Graduação em Psicologia Social. No primeiro contato com as mães das crianças com linguagem expressiva atrasada buscou-se verificar se as mesmas, assim como a criança a ser estudada, apresentavam os critérios necessários para a participação na pesquisa. E em seguida aplicou-se a entrevista semi-estruturada com as mães, onde buscou, além de propiciar um setting mais confortável para iniciar a pesquisa, obter maiores dados sobre o desenvolvimento da criança e sobre a sua família. 
$\mathrm{Na}$ segunda visita, houve a filmagem das díades em situação de brinquedo livre, que duraram 20 minutos, dos quais eram transcritos 10 minutos, excluindo-se os 5 primeiros e últimos minutos filmados. Depois de realizadas todas as vídeo-gravações das interações diádicas, iniciou-se o processo de análise dos dados.

\section{Procedimento de Análise dos dados}

A análise dos dados ocorreu em quatro etapas distintas:

1. Transcrição das observações das interações filmadas observando-se o contexto interacional. Estas transcrições foram realizadas segundo as normas do CHAT (Codes for Human Analysis of Transcripts), componente do programa computacional CHILDES (Child Language Data Exchange System); 2. Elaboração das categorias dos comportamentos comunicativos verbais e não-verbais das mães e das crianças evidenciados nas observações; 3 . Obtenção da freqüência dos comportamentos comunicativos das mães e das crianças através do CLAN, também componente do programa CHILDES; 4. Realização da análise quantitativa das frequiências obtidas através de teste de hipóteses do cálculo estatístico de COMPARAÇÃO DE DUAS PROPORÇÕES.

As transcrições das interações seguiram o formato do programa CHILDES (Child Language Data Exchange System) (Fletcher \& Macwhinney, 1997; Sokolov \& Snow, 1994). O CHILDES, Child Language Data Exchange System é um sistema computacional composto de três instrumentos que visam facilitar a troca de dados entre diferentes pesquisadores, aumentar a fidedignidade das transcrições e automatizar o processo de análise de dados (McWhinney, 1991; Sokolov \& Snow, 1994).

Para elaboração das categorias dos comportamentos comunicativos das mães e crianças, realizou-se uma leitura minuciosa dos protocolos, a fim de elaborá-las. Para a construção destas categorias, partiu-se das transcrições do CHAT, dos objetivos da pesquisa e da literatura existente sobre o tema, principalmente os estudos de Salomão (1996), Akhtar, Dunham e Dunham (1991), Salomão e Conti-Ramsden (1994), Lieven (1994), Borges (2000), Braz e Salomão (2002) e Fonseca (2003). A partir destas informações, foram elaborados três sistemas de categorias: o da contingência semântica da fala materna; o de seu estilo comunicativo verbal e dos comportamentos comunicativos verbais e não-verbais das crianças, ver em anexo 1.

Para análise estatística dos resultados por meio do teste de hipótese de comparação de duas proporções. Foram levantadas duas hipóteses: $\mathrm{H}_{0}, \mathrm{p}_{1}-\mathrm{p}_{2}=0$ e $\mathrm{H}_{1}$, $\mathrm{p}_{1^{-}}$ $\mathrm{p}_{2} \neq 0$. Fixamos o nível de significância a $5 \%$ e a distribuição para o teste de diferença entre proporções é a distribuição normal $(Z)$, nessa distribuição o valor de referência utilizado foi o intervalo entre $-1,96 \mathrm{e}$ $+1,96$, ou seja, o resultado do Zc estando entre os valores acima, aceita-se a hipótese $\mathrm{H}_{0}$, não estando, rejeita-se a hipótese $\mathrm{H}_{0}$. A variável de teste, evidentemente, seria a diferença entre as freqüências relativas das duas amostras disponíveis, p' ${ }_{1-}$ p' $_{2}$, onde estes seriam as proporções de cada população.

\section{RESULTADOS}

A apresentação dos resultados será realizada por meio da análise da comparação entre o estilo de fala materna utilizada no grupo das díades em que as crianças apresentavam linguagem expressiva atrasada e o estilo de fala materna utilizada no grupo das díades em que as crianças apresentavam a linguagem expressiva típica e da análise da participação dos dois grupos de crianças com sua mãe. Estes resultados foram extraídos a partir do cálculo de proporções dos enunciados verbais das mães e enunciados verbais e não-verbais das crianças de ambos os grupos; esse cálculo possibilitou a descrição de dados referentes às diferenças entre os grupos.

Neste sentido, a apresentação dos resultados será dividida em três momentos: a primeira constará da apresentação da análise do sistema de categorias acerca da contingência semântica da fala das mães dos dois grupos de crianças; a segunda constará os dados relativos ao sistema de categorias dos estilos comunicativos das mães dos dois grupos de crianças; e a terceira, e última parte, estará a análise da participação verbal e não-verbal das crianças de ambos os grupos com suas mães.

\section{Resultados das categorias maternas}

A proporção das categorias gerais da fala materna foi calculada pela frequiência total de cada tipo de enunciado materno, dividido pelo número total das categorias de fala materna dirigidas à criança, e multiplicado por cem. Depois de realizados esses cálculos, aplicou-se o teste de hipótese de comparação de duas proporções, descrito no item procedimentos de análise de dados.

Nesse sentido, serão apresentados os resultados das análises de proporção das verbalizações maternas dirigidas às crianças com atraso na linguagem expressiva e crianças com linguagem expressiva típica. Primeiramente será apresentada a análise do sistema de categorias da contingência semântica da fala materna e posteriormente a análise das categorias dos estilos verbais maternos. 


\section{Análise do sistema de categorias da contingência semântica da fala materna}

Os resultados do teste de hipótese de comparação de duas proporções, mostraram que existe diferença estatisticamente significante nos tópicos: continuidade, imitação e outros. O tópico continuidade obteve um $\mathrm{Zc}$ de -2,85; o tópico imitação o $\mathrm{Zc}$ foi de 3,83 e outros Zc de 4,88. Percebe-se que as mães das crianças com desenvolvimento típico utilizavam mais ver- balizações de continuidade do tópico de conversação do que as mães das crianças com desenvolvimento lingüístico atrasado. Porém, essas mães das crianças com atraso no desenvolvimento utilizavam mais as categorias imitação e outros do que as mães das crianças com desenvolvimento típico. Para melhor visualização dos resultados, estes serão apresentados em forma de figura demonstrando com melhor clareza as diferenças de proporção entre os dois grupos.

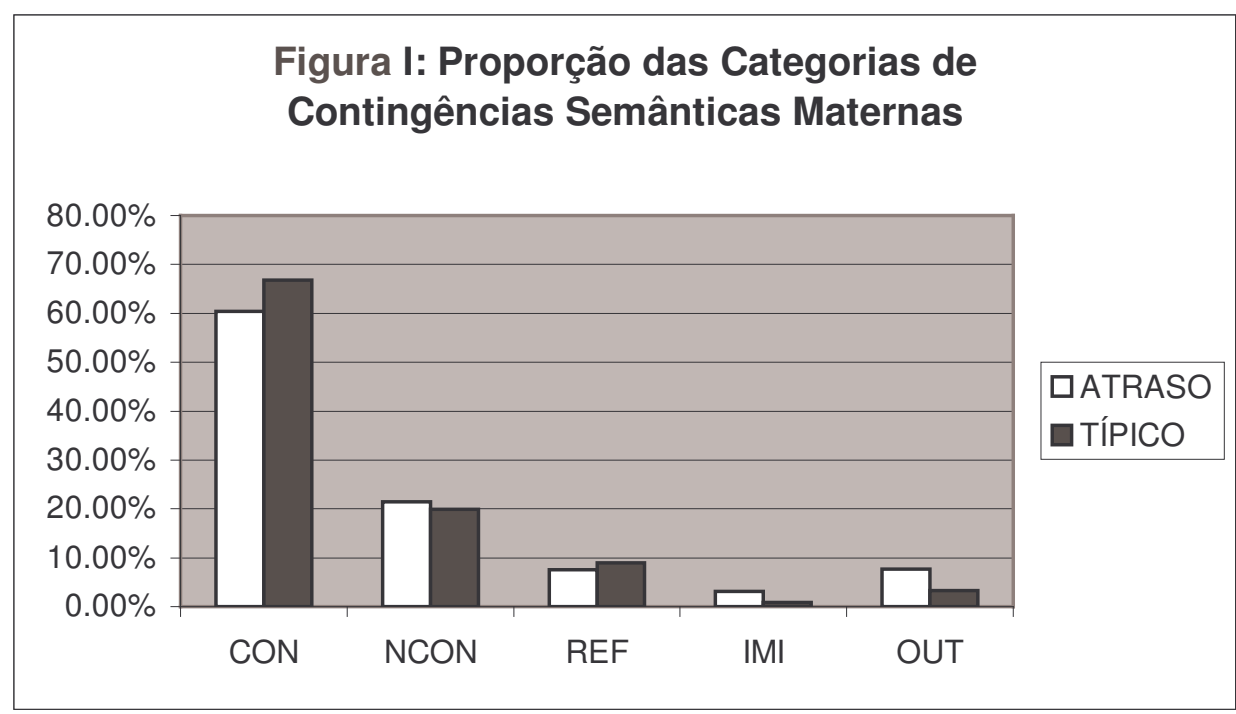

Figura I: Proporção das Categorias de Contingências Semânticas Maternas

Legenda: $\mathrm{COM}$ = continuidade; $\mathrm{NCON}$ = não continuidade; $\mathrm{REF}$ = reformulação; IMI = imitação; OUT = outros .

\section{Análise do sistema de categorias dos estilos} comunicativos verbais maternos

A análise se dará também em relação aos estilos comunicativos verbais maternos. Nos resultados observa-se que a única categoria utilizada pela mãe com mais freqüência nas crianças com desenvolvimento da linguagem expressiva atrasada foi o diretivo, com um
Zc de 9,4. Em relação às outras categorias requisição, feedback e comentários os Zc encontrados foram respectivamente $-6,19,-2$ e $-4,85$, e as mães apresentavam mais quando se comunicavam com as crianças de desenvolvimento típico da linguagem. A figura a seguir oferece melhor visualização quanto às diferenças das proporções dos dois grupos:

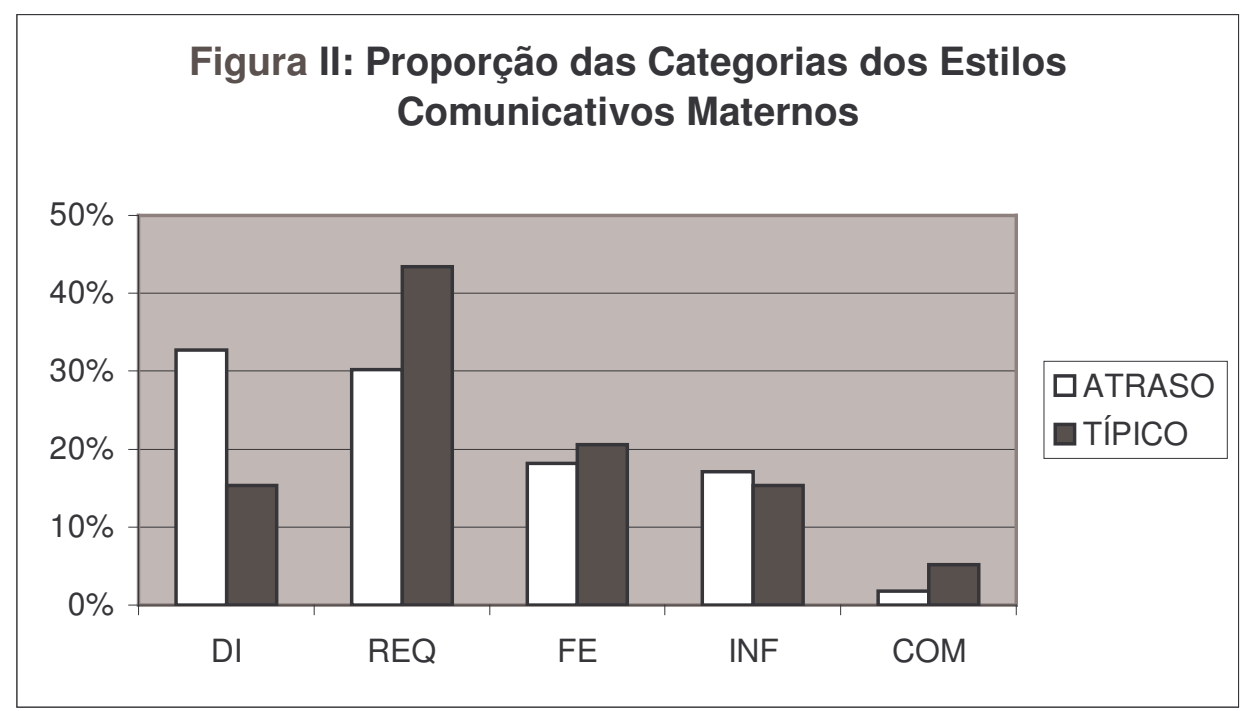


Figura II: Proporção das Categorias dos Estilos Comunicativos Maternos Legenda: $\mathrm{DI}=$ diretivos; $\mathrm{REQ}=$ requisições; $\mathrm{FE}=$ feedback $; \mathrm{INF}=$ informação; $\mathrm{COM}=$ comentários .

\section{Resultados das categorias dos comportamentos comunicativos das crianças}

De acordo com os resultados obtidos, verifica-se que as crianças com desenvolvimento típico da linguagem utilizavam mais as categorias fala espontânea $(Z c=-9,61)$ e resposta verbal adequada $(Z c=-2,17)$. A categoria resposta verbal inadequada $(Z c=1,42)$ demonstrou-se estatisticamente igual nos dois grupos de crianças. Já as crianças com atraso na linguagem expressiva obtiveram maior proporção nas categorias resposta não-verbal adequada $(\mathrm{Zc}=7,5)$, resposta não-verbal inadequada $(\mathrm{Zc}=2,85)$, repetição espontânea $(Z c=4,44)$, ausência de resposta $(Z c=2,14)$ e fala ininteligível $(\mathrm{Zc}=6,66)$.

A figura a seguir demonstra em forma de proporção estes resultados:

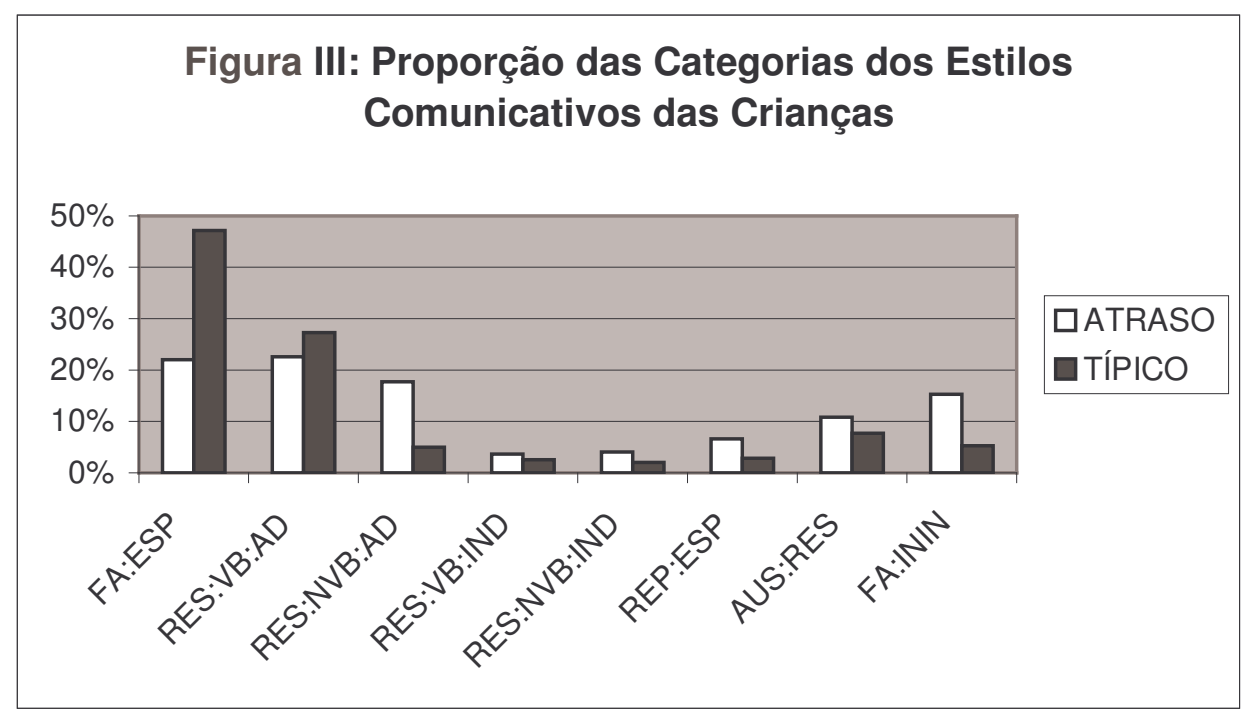

Figura III: Proporção das Categorias dos Estilos Comunicativos das Crianças

Legenda: FA:ESP = fala espontânea; RES:VB:AD = resposta verbal adequada; RES:NVB:AD = resposta não-verbal adequada; RES:VB:IND = resposta verbal inadequada; RES:NVB:IND = resposta não-verbal inadequada; REP:ESP = repetição espontânea; AUS:RES = ausência de resposta; FA:ININ = fala ininteligível.

\section{DISCUSSÃO}

A Perspectiva da Interação Social dos Estudiosos da Linguagem serviu como base para a análise desses resultados, ressaltando-se sempre a bidirecionalidade, uma vez que tanto as características da mãe como da criança podem interferir na interação mãe-criança. A criança é percebida dessa forma como parceira ativa na interação social e lingüística.

A discussão decorrerá em três partes: a discussão sobre as categorias de contingência semântica maternas; a discussão sobre os estilos comunicativos maternos; e, por fim, a discussão sobre os comportamentos comunicativos verbais e não-verbais das crianças.

\section{Categorias de contingência semântica materna}

As mães das crianças com desenvolvimento típico da linguagem emitiram mais verbalizações de continuidade de tópico que as mães das crianças com atraso no desenvolvimento da linguagem. Esses resulta- dos corroboram os de Salomão (1996), seus resultados indicaram que as mães que dão continuidade ao tópico de interesse da criança, oferecem à mesma maior oportunidade de participação na conversação.

Esse resultado encontra suporte no conceito de bidirecionalidade, pois as mães oferecerem continuidade às suas crianças à medida que compreende bem o que a criança diz. De acordo com Salomão e ContiRamsden (1994), pode haver uma dificuldade das mães se comunicarem com seus filhos, uma vez que nas crianças com distúrbio específico da linguagem existe uma longa distância entre o que essas crianças compreendem e falam, não indicando à mãe em que nível lingüístico se encontram, fazendo com que estas reduzam a densidade de sua fala com essas crianças.

A reformulação mostrou-se estatisticamente igual nos dois grupos de crianças, e esse resultado vai em direção oposta aos resultados encontrados na literatura (Nelson, Welsh, Camarata, Butkovsky \& Camarata, 1995; Nelson, 1977). Nestes estudos verificou-se que a fala das mães de crianças com atraso no desenvol- 
vimento da linguagem expressiva se concentrou especialmente em reformulações, ou respostas aos enunciados das crianças que acrescentavam o rearranjavam a fala das mesmas, estimulando o desenvolvimento da linguagem da criança. Porém, o resultado encontrado nesta pesquisa foi que as mães das crianças com atraso na linguagem tendiam a reformular menos a fala de seus filhos, o que de acordo com a literatura não facilita o desenvolvimento da linguagem.

A imitação mostrou-se mais freqüente na fala das mães de crianças com atraso no desenvolvimento da linguagem. Os estudos de Post (1993) indicaram que as mães repetiam de forma exata os enunciados bem elaborados das crianças, indicando que foram entendidos pela mãe. Pode-se supor, então, que as mães utilizavam mais essa categoria com as crianças com atraso numa tentativa de lhes indicar que aquela palavra proferida fora entendida pela mãe. Esse recurso então não seria tão utilizado pelas mães das crianças com desenvolvimento típico da linguagem porque estaria implícito que a mãe estaria compreendendo tudo que fora proferido pela criança.

\section{Categorias dos estilos comunicativos verbais maternos}

Verificou-se que os diretivos foram utilizados numa proporção maior com as crianças que apresentam atraso no desenvolvimento da linguagem. Esse resultado reforça os achados de Gallaway e Woll (1994) e Conti-Ramsden (1994), que concluíram que a fala dirigida a crianças atípicas era mais diretiva e menos contextualizada semanticamente do que a fala dirigida a crianças com desenvolvimento típico - esses achados foram confirmados em crianças com problemas auditivos, deficiências visuais, síndrome de Down, deficiências específicas da linguagem e deficiências da aprendizagem. Esses achados ainda sugerem que o ambiente lingüístico dessas crianças atípicas pode contribuir com suas dificuldades para a aprendizagem da linguagem, pois uma linguagem diretiva encontra-se normalmente associada a um progresso mais lento em crianças com desenvolvimento normal. No entanto, observou-se também que as crianças atípicas eram, por uma série de motivos, comunicadores espontâneos menos ativos e eficazes, de forma que a linguagem diretiva dos pais pode ser uma compensação inevitável da passividade da criança, incompreensibilidade ou baixo nível de respostas.

$\mathrm{O}$ uso de requisições mostrou-se em maior quantidade nas mães das crianças que apresentam o desenvolvimento típico da linguagem. Esse estilo funciona, em geral, como uma ferramenta materna para dar continuidade às atividades que estavam sendo realizadas pela díade, assim como para sustentar o diálogo com a criança, mantendo-a envolvida nas atividades.
De acordo com Snow (1977), Barnes, Gutfreund, Satterly e Wells (1983) e Pine (1994), o uso de requisições maternas motiva a criança a participar dos diálogos e estender seus recursos lingüísticos durante as interações. Assim, como as crianças com atraso no desenvolvimento lingüístico envolviam-se menos na conversação com suas mães, as mães requeriam menos respostas a essas crianças do que às crianças com desenvolvimento típico da linguagem.

No que tange ao uso de feedback, verificou-se que foi apresentado com maior freqüência às crianças que apresentam o desenvolvimento típico da linguagem. Esse resultado corrobora os estudos de Fagot e Hagan (1991), que mostraram que esse estilo de fala é encorajador do esforço comunicativo das crianças. Os resultados da pesquisa de Demetras, Post e Snow (1986), indicaram que os feedbacks, principalmente os de confirmação, dão continuidade ao diálogo com a criança, com o mínimo de interrupção, podendo funcionar como um feedback positivo implícito durante as interações, mantendo um diálogo com ela.

\section{Comportamentos comunicativos das crianças}

$\mathrm{Na}$ categoria fala espontânea verificou-se que as crianças com desenvolvimento típico da linguagem obtiveram uma proporção maior que o outro grupo de crianças. Era de se esperar, pois essas crianças passam a ser comunicadoras mais ativas, conseguindo expressar a maioria das palavras de forma compreensível para sua mãe.

No grupo de crianças com atraso no desenvolvimento da linguagem, a categoria fala ininteligível obteve maior proporção nas crianças que apresentam o desenvolvimento da linguagem atrasado, ou seja, estas pronunciam mais vocalizações que não são compreendidas pelas mães do que o outro grupo de crianças.

A categoria respostas verbais adequadas apresentou-se em maior proporção nas crianças com desenvolvimento típico da linguagem. Possivelmente essa proporção se mostrou maior a esse grupo porque foram dirigidos mais requisições por parte da mãe, explicando assim porque essas crianças apresentaram mais respostas verbais adequadas do que o outro grupo de crianças. Desta forma, as mães estavam adaptando suas perguntas às capacidades de respostas das crianças.

No que tange às categorias resposta não-verbal adequada e resposta não-verbal inadequada, as crianças com desenvolvimento da linguagem atrasado apresentaram em maior quantidade que o outro grupo. Esse resultado seria esperado já que as mesmas apresentariam maior facilidade em responder às solicitações da mãe de forma não-verbal. 
Foi observado que também nesse grupo de crianças a repetição espontânea foi apresentado com maior freqüência que no outro grupo de crianças. A literatura (Leonard, Schwartz, Folger, Newhoff \& Wilcox, 1979) aponta que esse enunciado não parece ser necessário para aquisição da linguagem e, portanto, de novos itens léxicos na fala espontânea das crianças. Para esses pesquisadores, antes de constituir um veículo para a aquisição do uso espontâneo de itens léxicos particulares, a imitação dos enunciados maternos parece indicar uma estratégia que habilita a criança a participar do ato comunicativo. Ou seja, essa categoria não induz o progresso da linguagem da criança, porém, pode servir como um recurso na tentativa de comunicação por parte da criança.

As crianças com atraso no desenvolvimento da linguagem também apresentaram em maior proporção a categoria ausência de resposta. Este resultado também era de se esperar já que essas crianças possuem uma dificuldade maior em utilizar a fala e assim em responder às requisições maternas e já que emitiram menos respostas verbais adequadas que o grupo de crianças com desenvolvimento típico, supõe-se que elas deixaram de responder a essas perguntas ou utilizaram a fala ininteligível, já que esses itens mostraram-se altos para esse grupo.

Segundo Snow (1977), o reconhecimento de que a criança tem capacidade para entender o que o adulto fala, e a insistência da mãe em introduzir um modelo conversacional em suas interações com a criança podem ajudar a explicar como esta adquire, desde cedo, a habilidade de ocupar um lugar na conversação e em outros tipos de interação. Esta participação da criança na conversação desempenha, portanto, um papel importante no comportamento materno.

Não se pode negar que tanto a fala das mães foi influenciada pelo feedback recebido pela criança, como a fala das crianças também foi restrita ao que era solicitado pelas mães nessa pesquisa. Observou-se que as mães, em geral, faziam um número maior de requisições às crianças que conseguiam respondê-las, ou seja, as crianças com desenvolvimento típico da linguagem. E já tentavam dirigir mais o comportamento das crianças com atraso no desenvolvimento da linguagem, uma vez que essas crianças eram comunicadores menos ativos e eram menos compreendidos pela mãe.

Destaca-se também a categoria continuidade, que obteve uma proporção bem mais elevada nas mães das crianças com desenvolvimento típico da linguagem. E segundo as pesquisas de Wandell e Wilson (1987), as mães que respondem contingentemente ao comportamento dos seus filhos thes proporcionam mais experiências de tomar a direção na conversação, assim como estabelecem uma maior segurança na relação mãecriança.

O que ressaltamos nos resultados desta pesquisa foi a importância do input materno para o desenvolvimento normal da criança e quais estilos são mais utilizados com as crianças com atraso no desenvolvimento da linguagem. Os resultados mostraram que a reformulação foi usada nos dois grupos com a mesma frequiência. Considerando-se que o grupo das crianças com atraso deveriam receber mais reformulação, a falta desta dificultaria o desenvolvimento típico da linguagem.

A fala diretiva está diretamente relacionada com a fala espontânea da criança. Uma vez que as crianças com atraso eram comunicadoras menos ativas, as mães tendiam a dirigir numa maior proporção os comportamentos destas crianças, o que não é favorável para o desenvolvimento típico da linguagem.

Essa pesquisa vem reforçar a necessidade de estudos nessa área, com esta população, e aponta a dificuldade que os profissionais e estudiosos desta área possuem em estabelecer conceito e etiologia bem definidos para o atraso no desenvolvimento da linguagem expressiva, ressaltando-se ainda a escassez de pesquisas com esta população aqui no Brasil.

\section{ANEXO 1 \\ Legenda: MOT $($ mother $)=$ mãe; $\mathrm{CHI}($ child $)=$ filho}

\section{Sistema de categorias de contingências semânticas da fala materna}

1. Enunciados de Continuidade (CON): São os enunciados expressos pela mãe, posteriores à fala prévia da criança, que dão continuidade à verbalização infantil, uma vez que abordam o mesmo conteúdo semântico presente nesta. Esses enunciados não se apresentam como resultados de reformulações ou imitações da fala infantil (ContiRamsden, 1990). Ex.: CHI: o urso ficou. MOT: aonde?

2. Enunciados de não-continuidade (NCON): São enunciados expressos pela mãe, posteriores à fala da criança, que não dão continuidade à verbalização infantil, em vista de a mãe introduzir um novo conteúdo semântico à conversação (Conti-Ramsden, 1990). Ex.: CHI: é de mamãe? MOT: sente aqui, venha.

3. Reformulação (REF): Enunciados expressos pela mãe, posteriores à fala da criança, que dão continuidade à verbalização infantil, uma vez que se referem ao mesmo conteúdo semântico exposto pela criança. Entretanto, estes enunciados caracterizam-se por apresentarem mudanças estruturais da verbalização precedente da criança (Lieven, 1994). Foram considerados como enunciados de reformulação até os dois enunciados maternos subseqüentes ao enunciado da criança. Ex.: CHI: doi, teis... MOT: um, dois, três e já.

4. Imitação (IMI): Enunciados expressos pela mãe, posteriores à fala prévia da criança, que dão continuidade à 
verbalização da criança, uma vez que se referem ao mesmo conteúdo semântico exposto pela criança. Estes enunciados caracterizam-se por apresentarem como resultado de uma imitação integral da verbalização infantil, considerando-se até dois enunciados maternos subseqüentes ao enunciado da criança (Salomão e Conti-Ramsden, 1994). Ex.: CHI: $e$ agora? MOT: e agora?

5. Outros (OUT): São enunciados expressos pela mãe que vem em seqüência à fala ininteligível da criança, oferecendo uma seqüência no diálogo. Esses enunciados não devem ser de reformulação e nem pedidos de esclarecimentos. Ex.: CHI: xxx. xxx (fala ininteligível). MOT: desligou?

\section{Sistema de categorias dos estilos comunicativos maternos}

1. Diretivos (DI): São os enunciados expressos pela mãe, de forma imperativa, tendo como função chamar a atenção, regular ou dirigir as verbalizações ou comportamentos da criança (Akhtar, Dunham \& Dunham, 1991; Salomão \& Conti-Ramsden, 1994).

a) DI: Instrução (DI:INS): São os enunciados em que a mãe ordena à criança o que ela deve fazer em uma determinada atividade, indicando o nome de um lugar, nomeando objetos e/ou descrevendo suas características. Usualmente, essas instruções estão relacionadas aos brinquedos ou brincadeiras que estão sendo utilizadas. Ex.: MOT: Pegue aquela bolinha ali ó, a bolinha.

b) DI: Solicitação de Atenção (DI:SA): Enunciados expressos pela mãe, onde a mesma tenta chamar a atenção da criança, apresentando algum brinquedo, pronunciado seu nome ou utilizando alguma palavra que desperte o interesse dela por algo, como por exemplo: "olhe, veja, escute". Ex.: MOT: Ó Kevin o carro, ó.

2. Requisições (REQ): São enunciados expressos pela mãe, de forma explícita ou implícita, que têm por função solicitar respostas verbais e/ou não-verbais da criança. Estas solicitações normalmente são utilizadas para obtenção de informações sobre objetos, situações e ações, e ainda, para instigar a participação da criança na interação (Salomão e Conti-Ramsden, 1994).

a) REQ: Resposta Específica (REQ:RE:ES): Enunciados expressos pela mãe que requerem da criança uma resposta específica, como sim/não, quero/não quero, pode/não pode, o nome de um objeto ou pessoa quando está sendo mostrado, ou ainda, as características destes, na intenção que a criança participe da interação (Salomão \& ContiRamsden, 1994). Estes enunciados apresentam-se, geralmente, como questões fechadas. Ex.: MOT: vai brincar com o priminho é?

b) REQ: Resposta Geral (REQ:RES:GE): Enunciados expressos pela mãe que requerem da criança informações gerais acerca da localização de um objeto ou pessoa, de uma ação ou de uma situação. Nessa categoria, não estão inclusas as requisições em que a mãe solicita sugestões ou esclarecimentos da criança. Ex.: MOT: o que você quer jantar hoje?

c) REQ: Sugestão (REQ:SUG): São enunciados expressos pela mãe que se apresentam com uma requisição geral, uma vez que solicitam da criança respostas gerais acerca de objetos, pessoas, ações ou situações. Entretanto, esses enunciados caracterizam-se por apresentarem em seu conteúdo solicitações de sugestão da criança acerca de uma determinada atividade ou objeto durante a interação. Ex.: MOT: vamo cantá, vamo?

d) REQ: Esclarecimento (REQ:ESC): Esses enunciados caracterizam-se por solicitarem explicação da fala prévia da criança, indicando o não entendimento desta por parte da mãe, geralmente apresentam-se após uma fala ininteligível. Ex.: MOT: é o quê?

e) REQ: Complementação (REQ:COM): São enunciados expressos pela mãe onde a mesma solicita que a criança complete seu enunciado ou sua sentença (Salomão e ContiRamsden, 1994). Ex.: MOT: eu sou a roda $+\ldots$

3) Feedback (FE): Enunciados expressos pela mãe, cuja função é a de responder às solicitações da criança ou avaliar o seu comportamento como certo ou errado. Estes enunciados podem apresentar-se como uma resposta específica a uma questão, um pedido ou uma ordem da criança, ou ainda, como uma aprovação ou desaprovação da fala e/ou gesto desta (Pine, 1992; Salomão \& Conti-Ramsden, 1994).

a) FE: Aprovação Verbal (FE:AP:VB): São enunciados expressos pela mãe, onde a mesma aprova um enunciado ou uma ação emitidos pela criança (Salomão \& ContiRamsden, 1994). Também serão considerados nesta categoria aqueles enunciados maternos que repetem a fala prévia da criança e que apresentam uma entonação que indique aprovação. Ex.: MOT: Ponto! Muito bem!

b) FE: Desaprovação Verbal (FE:DAP:VB): São enunciados expressos pela mãe de reprovação, que têm por finalidade responder aos enunciados ou ações da criança, que do pondo de vista não estão corretos e/ou não são esperados. Ex.: MOT: que coisa feia, menino.

c) FE: Resposta Verbal (FE:RES:VB): Enunciados verbais expressos pela mãe, que respondem a questões, pedidos ou a ordens formuladas pelas crianças (Salomão e Conti-Ramsden, 1994). Ex.: CHI: ele parou? MOT: parou.

d) FE: Confirmação (FE:CONF): Enunciados onde a mãe repete as respostas da criança, com a finalidade de confirmar-lhe as verbalizações, embora demonstrem tê-las entendido. Estas respostas podem apresentar-se de forma interrogativa (Salomão \& Conti-Ramsden, 1994). Ex.: CHI: no shopping. MOT: no shopping?

4) Informar (INF): Enunciados expressos pela mãe onde a mesma fornece informações para a criança acerca dos nomes e das características de objetos ou de pessoas, propriedades, localizações e possessões de objetos, demonstrando ou descrevendo uma ação (Conti-Ramsden, 1990). Ex.: MOT: assim tú tá fazendo uma montanha, tá parecendo uma montanha de lápis.

5) Comentários (COM): Trata-se de enunciados expressos pela mãe sobre as próprias ações ou sobre o comportamento da criança, podendo ser dirigidos ao observador (Salomão \& Conti-Ramsden, 1994). Ex.: MOT: ele não quer papo com o violão hoje.

\section{Sistema de categoria dos estilos comunicativos das crianças}


1. Fala Espontânea (FA:ESP): Enunciado da criança que não é precedido por uma questão, um pedido, ou uma ordem da mãe nem é o resultado de uma imitação das verbalizações prévias desta (Salomão \& Conti-Ramsden, 1994). Ex.: CHI: eu não quero mais brincá com o carro porque ele machuca.

2. Resposta (RES): São enunciados expressos pela criança, que têm a função de responder a uma questão, a um pedido ou a uma ordem da mãe. Considera-se a resposta correta ou incorreta segundo o ponto de vista da mãe (Salomão \& Conti-Ramsden, 1994).

a) Resposta Verbal Adequada (RES:VB:AD): Enunciados verbais adequados ao contexto, segundo ponto de vista da mãe. Não serão consideradas respostas de imitação ao enunciado prévio da mãe, que não seja uma requisição para repetir (Salomão \& Conti-Ramsden, 1994). Ex.: MOT: O que é isso aí? CHI: A vaca.

b) Resposta não-verbal adequada (RES:NVB:AD): Comportamentos que respondem, de forma adequada, ao enunciado prévio da mãe quanto ao que foi solicitado por esta. Ex.: MOT: é o quê, meu filho? Tirar os óculos? CHI: o filho balança a cabeça negativamente.

c) Resposta verbal inadequada (RES:VB:IND): Enunciados das crianças que respondem verbalmente e, de modo inadequado, do ponto de vista da mãe, ao enunciado prévio da mesma, quanto ao contexto, à semântica e ao conteúdo solicitados por este. Ex.: MOT: pronto! Cadê sua barbie? CHI: me dê o carrinho!

d) Resposta não-verbal inadequada (RES:NVB:IND): Comportamentos que respondem, de forma inadequada, ao enunciado prévio da mãe quanto ao que foi solicitado por esta (Salomão \& Conti-Ramsden, 1994). Ex.: MOT: quer sentar aqui? CHI: corre em direção à cama com a boneca nos braços, pára e olha em direção à mãe.

3. Ausência de Resposta (AUS:RES): Caracteriza-se pela ausência de respostas por parte da criança às perguntas formuladas pela mãe. Esta categoria será considerada após o tempo de dois segundos da questão emitida pela mãe, ou até que a criança verbalize uma fala iniciativa. Ex.: MOT: como é que o gatinho anda? Ande aí como o gatinho. CHI: olha em direção à mãe.

4. Fala ininteligível (FA:ININ): São enunciados da criança que se torna impossível compreender o que o falante está dizendo.

\section{REFERÊNCIAS}

Akhtar, N. Dunham, F. \& Dunham, P. (1991) Directive interactions and early vocabulary development: the role of joint attentional focus. Journal of child language, 18, 41-49.

Barnes, S., Gutfreund, M, Satterly, D. \& Wells, G. (1983). Characteristics of adult speech wich predict children's language development. Journal of Child Language, 10, 65-84.

Borges, L. C. (2000). Estilos comunicativos apresentados por díades mãe-criança de nível socioeconômico médio e baixo. Dissertação de mestrado não publicada. Universidade Federal da Paraíba, João Pessoa.

Braz, F. S. \& Salomão, N. M. R. (2002). A fala dirigida a meninos e meninas: um estudo sobre o input materno e suas variações. Psicologia: Reflexão e Crítica, 15, 2, 333-344.
Conti-Ramsden, G. (1994). Language interaction with atypical language learners. Em B. Richards \& C. Gallaway (Orgs.), Input and interaction in language acquisition (pp. 183-196). Cambridge: University Press.

Craig, H. K. (1997). Deficiências Pragmáticas. Em P. Fletcher \& B. Mac. Whinney (Orgs.), Compêndio da linguagem da criança (pp. 503-516). Porto Alegre: Artes Médicas.

Demetras, M. J.; Post, K. N. \& Snow, C. E. (1986). Feedback to first language learners: the role of repetitions and clarification questions. Journal of Child Language, 13, 275-292.

Fagot, B. A. \& Hagan, R. (1991). Observations of parental reactions to sex-stereotyped behaviors: age and sex effects. Child Development, 6, 617-628.

Fletcher, P. \& MacWhinney. B (1997). Compêndio da linguagem da criança. Porto Alegre: Artes Médicas.

Fonseca, P. N. (2003) Interação pai/criança e mãe/criança: uma análise comparativa entre estilos comunicativos. Dissertação de mestrado não publicada. Universidade Federal da Paraíba, João Pessoa.

Gallaway, C. \& Woll, B. (1994). Interaction and childhood deafness. Em C. Gallaway \& B. Richards (Orgs.), Input and interaction in language acquisition (pp. 197-218). London: Cambridge University Press.

Garton, A. F. (1992). Social interaction and the development os language and cognition. Hillsdale, USA: Lawrence Eribaum Associates, Publishers.

Leonard, L. B., Schwartz, R. G., Folger, M. K., Newhoff, M. \& Wilcox, M. J. (1979). Children's imitations of lexical items. Child Development, 50, 19-27.

Lieven, E. V. M. (1994). Crosslinguistic and crosscultural aspects of language addressed to children. Em C. Callaway e B. Richards (Org.), Input and Interaction in Language Acquisition (pp. 56-73). London: Cambridge University Press.

Luque, A. \& Vila, I. (1997). Desenvolvimento da linguagem. Em C. Coll; J. Palacios \& A. Marchesi (Orgs.), Desenvolvimento Psicológico e Educação I (pp. 149-164). Porto Alegre: Artes Médicas.

MacWhinney, B. (1991). The CHILDES project: tools for analyzing talk. Hillsdal, NJ: Lawrence Eribaum Associates.

Moseley, M. J. (1990). Mother-child interaction with preschool language delayed children: stucturing conversations. Journal Commun Disord, 23, 187-203.

Mussem, P., Conger, J., Kagan, J. \& Huston, A. (1995). Desenvolvimento e personalidade da criança. São Paulo: Harbra, 641p.

Nelson, K. E. (1977). Facilitating children's syntax acquisition. Development Psychology, 13, 101-107.

Nelson, K. E., Welsch, J., Camarata, S. M., Butkovsky, L. \& Camarata, M. (1995). Available input for language impaired children and younger children of matched language levels. First Language, 15 (pp. 1-17).

Pine, J. M. (1994). The language of primary caregivers. Em Gallaway \& B. J. Richards (Orgs.), Input and interaction in language acquisition (pp. 15-37). London: Cambridge University Press.

Post, K. N. (1993). Negative evidence in the language learning environment of laterborns in a rural Florida community. Em J. Sokolov \& C. Snow (Orgs.), Handbook of research in language developmente using CHILDES (pp. 132-173). Hillsdale, NJ: Lawrence Erlbaum.

Rice, M. L. (1989). Children's language acquisition. American Psychologist, 44, 149-156. 
Salomão, N. M. R. (1996). Interation between mothers and children with specific language impairtment: A longitudinal study. University of Manchester: England.

Salomão, N. M. R. \& Conti-Ramsden, G. (1994). Maternal speech to their offspring: SLI children and their younger siblings. Scandinavian Journal of Logopedios and Phonology, 19 (1117).

Snow, C. (1972). Mothers' speech to children learning language. Child Development, 43, 549-565.

Snow, C. (1977). Mothers' speech research: fron input to interaction. Em C. E. Snow \& C. A. Ferguson (Orgs.), Talking to Children: language input and acquisition. (pp. 31-49). Cambridge: Cambridge University Press.

Snow, C. (1997). Questões no estudo do input: sintonia, universalidade, diferenças individuais e evolutivas, e causas necessárias. Em P. Fletcher \& B. MacWhinney (Org.), Compêndio da Linguagem da Criança. (pp. 153-163). Porto Alegre: Artes Médicas.

Sokolov, J. L. \& Snow, C. E. (1994). The changing role of negative evidence in theories of language development. Em C.
Gallaway \& B. J. Richards (Orgs.), Input and interaction in language acquisition (pp. 38-55). London: Cambridge University Press.

Stark, R. E. \& Tallal, P. (1981). Selection of children with specific language deficits. Journal of Speech and Hearing Disorders, 46, 114-133.

Wandell, D. L \& Wilson, K. S. (1987). Infants' interactions with mother, sibling, and peer: contrasts and relations between interaction systems. Child Development, 58, 176-186.

\section{Sobre as autoras:}

Renata Meira Véras: Mestra em Psicologia Social pela Universidade Federal da Paraíba (UFPB).

Nádia Maria Ribeiro Salomão: Doutora em Psicologia pela Universidade de Manchester (Inglaterra), Docente do Programa de PósGraduação em Psicologia Social - Universidade Federal da Paraíba.

Endereço para correspondência: Departamento de Psicologia - Mestrado em Psicologia Social - Universidade Federal da Paraíba, UFPB, João Pessoa-PB - CEP: 580599-00. Endereço eletrônico: renameira@ig.com.br. 